\title{
REMOTE SENSING OF SEA ICE
}

\author{
Lars-Anders Breivik $^{(1)}$, Tom Carrieres ${ }^{(2)}$, Steinar Eastwood ${ }^{(1)}$, Andrew Fleming ${ }^{(3)}$, Fanny Girard-Ardhuin ${ }^{(4)}$, \\ Juha Karvonen $^{(5)}$, Ron Kwok ${ }^{(6)}$, Walter N. Meier ${ }^{(7)}$, Marko Mäkynen ${ }^{(5)}$, Leif Toudal Pedersen ${ }^{(8)}$, \\ Stein Sandven ${ }^{(9)}$, Markku Similä ${ }^{(5)}$, Rasmus Tonboe ${ }^{(8)}$ \\ (1) Norwegian Meteorological Institute, P.O.Box. 43, N-0313 Blindern, Norway, \\ Email: l.a.breivik@met.no, s.eastwood@met.no \\ (2) Canadian Ice Service, 373 Sussex Drive, Block E, Third Floor, Ottawa, Ontario, K1A 0H3, Canada, \\ Email: Tom.Carrieres@ec.gc.ca \\ ${ }^{(3)}$ British Antarctic Survey, High Cross, Madingley Road, Cambridge, CB3 OET, United Kingdom, \\ Email: AHF@bas.ac.uk \\ (4) Laboratoire d'Océanographie Spatiale, IFREMER (French Institute for the Exploitation of the Sea/Institut Français \\ de Recherche pour l'Exploitation de la Mer), BP 70, 29280 Plouzané, France, Email: Fanny.Ardhuin@ifremer.fr \\ ${ }^{(5)}$ Finnish Meteorological Institute, P.O. Box 503, FI-00101 Helsinki, Finland, Email: juha.karvonen@fmi.fi, \\ Marko.Makynen@fmi.fi, Markku.Simila@fmi.fi \\ (6) Jet Propulsion Laboratory, California Institute of Technology, 4800 Oak Grove Drive, Pasadena, \\ California 91109, USA, Email: ron.kwok@jpl.nasa.gov \\ (7) National Snow and Ice Data Center, Univ. of Colorado, UCB 449, Boulder, CO 80309, USA, Email: walt@nsidc.org \\ ${ }^{(8)}$ Danish Meteorological Institute, Lyngbyvei 100, 2100 Copenhagen, Denmark, Email: ltp@dmi.dk, rtt@dmi.dk \\ ${ }^{(9)}$ Nansen Environmental and Remote Sensing Center, Thorm $\phi$ hlensgt. 47, N-5006 Bergen, Norway, \\ Email: stein.sandven@nersc.no
}

\section{INTRODUCTION}

Sea ice data from satellites represent one of the longest earth observation records from space. The variations in temperature, emissivity and reflectivity of sea ice and the differences compared to the surrounding open ocean make it an ideal application of remote sensing. Several techniques and instruments have been developed and successfully utilized and today it is impossible to imagine operational sea ice monitoring and analysis without satellite data. However, as the use expands and need for knowledge moves forward, remote sensing of sea ice faces new challenges.

This paper describes the use of satellite data in remote sensing of sea ice with a focus on operational applications. It provides an overview of status, recent developments and future challenges to improve sea ice monitoring from satellites.

\section{LARGE SCALE ICE MONITORING}

\subsection{Ice concentration}

Microwave radiometers have monitored sea ice daily since the 1970s. The sea ice concentration analysis based on passive microwave from SMMR (Scanning Multichannel Microwave Radiometer) (from 19791988) and SSM/I (Special Sensor Microwave/Imager) (from 1987) are the backbone of sea ice monitoring over the last three decades in both Arctic and Antarctic. The decline in Arctic sea ice extent, with the minimum in September 2007, is documented by the time series of SMMR and SSM/I ice concentration data.

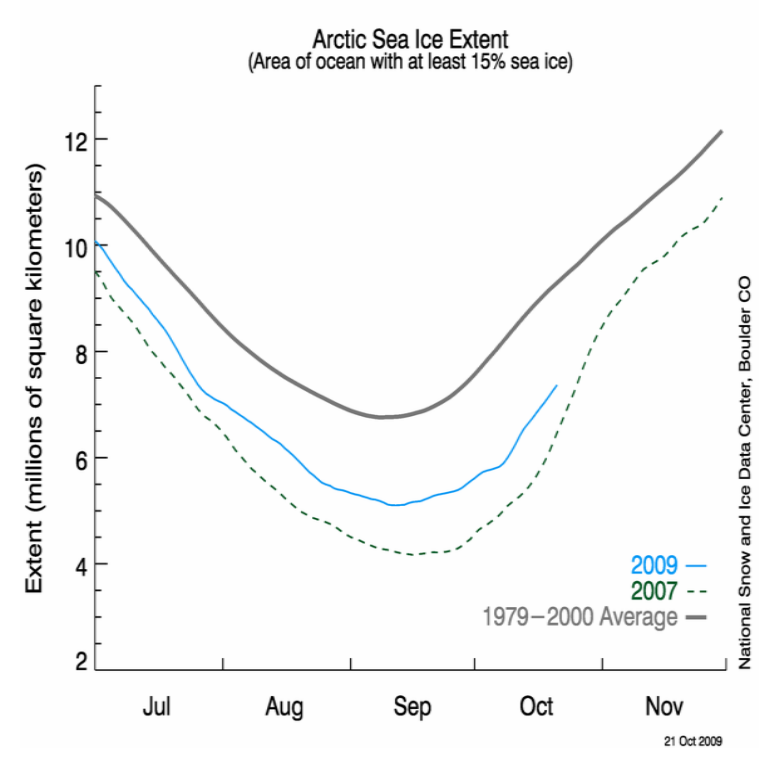

Figure 1: Arctic summer sea ice extent, thick line: the 1979 - 2000 average, dashed line: 2007 and thin blue line: 2009.

Figure 1 shows the September monthly Arctic average sea ice extent (1978-2008). Ice extent is here defined as the total area of ocean covered with at least $15 \%$ ice. Figure 2 shows Arctic ice concentrations for September 2005, 2006, 2007 and 2008. In Antarctica, the total area of sea ice has changed little in the last three decades, but important changes in the distribution of sea ice have been observed in the Southern Ocean [1]. 


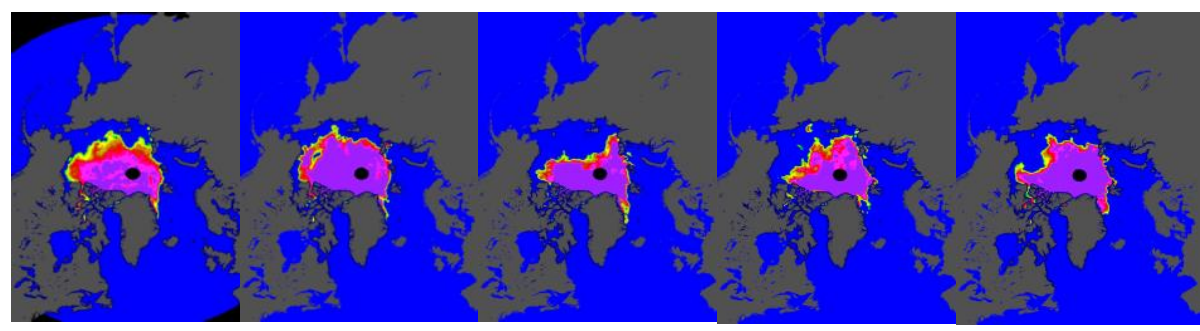

Figure 2: Ice concentration in September 2005- 2009. From the OSI SAF (Ocean and Sea Ice Satellite Application Facility). Sea ice concentration data are available from several providers such as NSIDC (National Snow and Ice Data

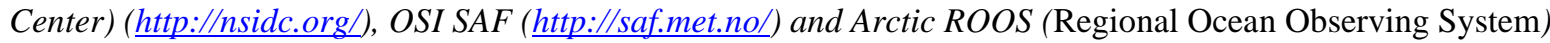

(http://arctic-roos.org).

The mean accuracy of algorithms used to compute ice concentration from SSM/I data is good, typically 1-6\% in winter [2]. However, inter comparison of different algorithms shows up to $10 \%$ differences in the estimated ice areas suggesting that algorithms perform differently under certain conditions [3]. Their sensitivity to emissivity and thermometric temperature of the target depends on the selection of brightness temperatures at different polarisations and frequencies [4]. In summer season, the onset of melting and appearance of melt ponds results in underestimation of ice concentration. Corrections for this depend of identifying the state of the ice surface and ponding, which can be achieved by use of microwave radars [5]. The computed ice concentration accuracy is further degraded by atmospheric constituents like cloud liquid water. Reliable estimates of atmospheric cloud liquid water and the ice brightness temperature variability are not readily available and it is therefore important to find ice concentration algorithms that are least sensitive to these atmospheric and surface properties. Other parameters, such as atmospheric water vapour and open ocean surface wind, are quantified rather well by numerical weather prediction models. It is therefore feasible to correct brightness temperatures for the influence of these effects using radiative transfer models before computing the ice concentration [6]. All use of the data requires estimates of the errors and uncertainties due to e.g. atmospheric contribution, emissivity uncertainty and footprint mixing.

It is important to continue to improve and validate the retrieval algorithms, taking also into account that a thinning of the ice cover may lead to increased errors in the retrievals. And last but not least, the access to microwave imager data for sea ice must be consistently secured. The DMSP (Defense Meteorological Satellite Program) (SSM/I, SSMIS (Special Sensor Microwave Imager / Sounder)) program will provide data until at least 2017. Higher spatial resolution is obtained from the AMSR-E (Advanced Microwave Scanning Radiometer-EOS (Earth Observing System) instrument which will be followed up by AMSR-2 in 2011 (http://www.jaxa.jp/projects/sat/gcom/). It is important that these missions are followed up in operational satellite programs (e.g. NPOESS (Polar-orbiting Operational Environmental Satellite System) and postEPS (EUMETSAT (European Organisation for the Exploitation of Meteorological Satellites) Polar System)).

\subsection{Ice thickness and ice types}

Ice thickness is needed to compute the total ice volume, quantify heat fluxes between ocean and atmosphere as well as to plan operations in the ice. In the last 15 years radar altimeter data from ERS (European Remote-Sensing Satellite) and ENVISAT (Environmental Satellite) has been analyzed to retrieve large-scale ice thickness, confirming the observed thinning of the Arctic sea ice cover [7]. New satellite altimeters provide improved sea ice freeboard for retrieval of ice thickness (ICESat (Ice, Cloud, and land Elevation Satellite) and CryoSat-2 (Cryospheric Satellite)). SAR (Synthetic Aperture Radar), scatterometer and microwave radiometer cannot be used directly for ice thickness retrieval. However, the ice salinity and roughness are characteristic for different ice ages/types that can be proxies for ice thickness categories [6] and [8]. New ice can be mapped by combinations of scatterometer and radiometer data [9] and the thickness of thin ice can be retrieved from passive microwave data [10] and [11]. SAR data are used for mapping ice deformation and ridged ice [12]. Combinations of ice drift data with ice extent and ice type data in bookkeeping models can be used to assess ice deformation and ice age and even salt flux to the upper ocean [13]. Ice thickness information are retrieved from ice age and type combined with Lagrangrian tracking of parcels using ice motion algorithms. By building up parcels over several years, ice age distributions can be tracked [14].

\subsection{Ice drift}

Ice drift datasets are used in climate models for validation and to estimate sea ice flux [15] and [16] and to improve sea ice modelling [17]. Sea ice drift has been monitored by the International Arctic Buoy Program since 1979 where about twenty buoys per year are deployed on ice floes in the interior of the Arctic 
Ocean. Global coverage can only be obtained from satellite data, giving ice displacement vectors with spatial and temporal resolution defined by the input data ([18], [19] and [20]). The mostly used data are the $85 \mathrm{GHz} \mathrm{SSM} / \mathrm{I}$ and $89 \mathrm{GHz}$ AMSR-E; however, these high frequency channels are sensitive to atmospheric and surface moisture limiting observations to the cold period from October to April. Several ice displacement algorithms have been developed such as wavelet analysis and Maximum Cross Correlation between successive maps. Drift estimates are validated against buoy data. It is shown that the uncertainty is related to grid cell size.

To remove outliers, a correlation coefficient threshold is imposed, and a control with wind direction is often applied since mean sea ice drift is strongly linked with the large-scale winds in dynamical areas. Optimal interpolation techniques can also be applied to remove outliers and produce more coherent daily ice motion fields [21].

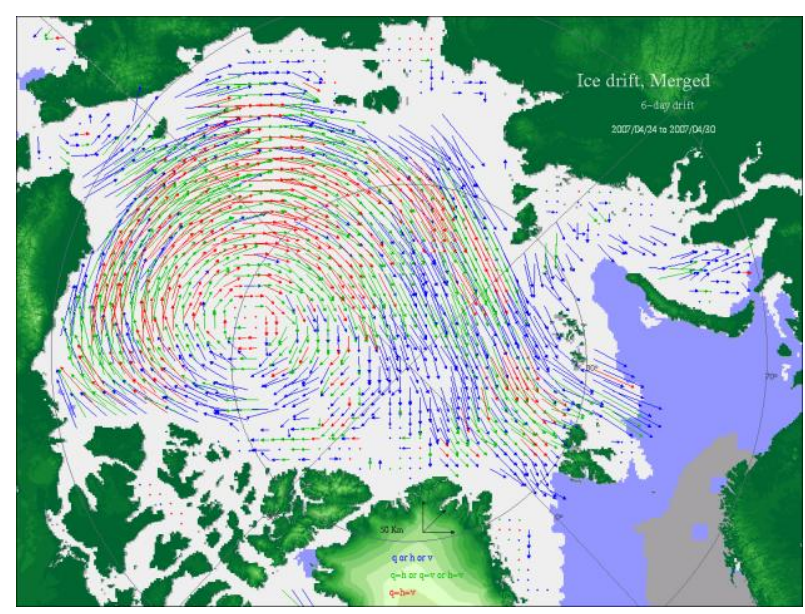

Figure 3: "Merged" Arctic sea ice drift from SSM/I radiometer drift field (2 channels) and

SeaWinds/QuikSCAT (NASA's Quick Scatterometer) scatterometer drift field at 6 day-lag on April $24^{\text {th }}-30^{\text {th }}$, 2007. Grid spacing is $62.5 \mathrm{~km}$. Drift vectors less than one pixel are marked with a cross. In red: identical drift vector for the three products, in green: identical drift vector for two products, in blue: selection or validation of a single drift vector. IFREMER/CERSAT

(French Institute of Research for the Exploitation of the Sea-Institut Français de Recherche pour l'Exploitation de la Mer/Center for Satellite Exploitation and Research).

Scatterometer data are also used to estimate sea ice drift from daily backscatter maps [20]. A product example is shown in Fig. 3: Merging of radiometer and scatterometer drift fields at the same resolution improves the reliability of each vector, increases the data density, lengthens the usable time period, and enables discrimination of the vector outliers.
Estimation of ice drift through Fram Strait is a major issue since this strait is the main exit gate for ice export from the Arctic basin to the Sub-Arctic seas [16]. Ice drift through the strait has been estimated using passive microwave data since 1978 [22]. Since 2004 wide swath SAR data from ENVISAT have been used to estimate ice drift with improved spatial resolution, about $20 \mathrm{~km}$, with three-day interval at $79 \mathrm{~N}$ [23]. SAR-derived ice drift vectors can be retrieved yearround. The SAR vectors are also capable of resolving the cross-strait velocity profile. By combining ice concentration profile from passive microwave data with drift profile from SAR, the area flux across $79 \mathrm{~N}$ can be estimated. Time series of ice area flux is now available for 3 decades from passive microwave data, and by adding SAR-derived ice fluxes for the last five years; it is possible to validate the accuracy of the passive microwave retrievals. The final goal is to estimate the ice volume flux through the strait on seasonal and interannual scale, which can be done by combining area flux data with thickness data. With satellite-based ice thickness from ICESat and upcoming thickness data from CryoSat-2 (see below), it will be possible to monitor ice volume fluxes through the strait.

In Antarctic, ice drift retrieval is more difficult due to faster ice-drift, more variable ice conditions, and more moisture in the atmosphere. Validation is also more difficult due to the lack of buoy observations for comparison. However, Antarctic fields have been produced [24], though with higher errors than for the Arctic. Further improvements of sea ice drift estimations can be expected by use of new sensors with better ground resolution and pixel size, and more optimized integration of various data.

\subsection{New opportunities for ice volume measurements}

The ICESat mission, launched in 2003, carries a laser altimeter system with two channels. The elevation profiles are sensitive to new openings in the ice cover as well as to surface relief of the floating ice. With approximately $2 \mathrm{~cm}$ precision in the quality of ICESat elevations, differencing the measured ice elevation from that of the local sea surface gives a good estimate of the total freeboard, i.e. the vertical distance between the sea surface and the air/snow interface. Together with an estimate of the snow loading, the total ice thickness can be estimated. Treatment of the practical issues associated with freeboard retrieval and estimation of ice thickness can be found in [25] and [26]. Figure 4 shows the spatial distributions of sea ice thickness derived from two ICESat campaigns acquired during the fall 2005 and the other during the winter 2006. Broadly, all the thickness fields show a distinct transition in thickness between the seasonal and perennial ice zones. The contrast in thickness is 
especially pronounced in fall because of the larger differences in thickness between the old ice (next to Ellesmere Island and the Greenland Coast) and seasonal ice (central Arctic and Siberian coast). At this writing, there have been 14 operational ICESat periods.
Investigators are moving in the direction of larger scale validation and use of these derived fields to understand the thickness and volume changes of the rapidly declining ice cover [27]. a)

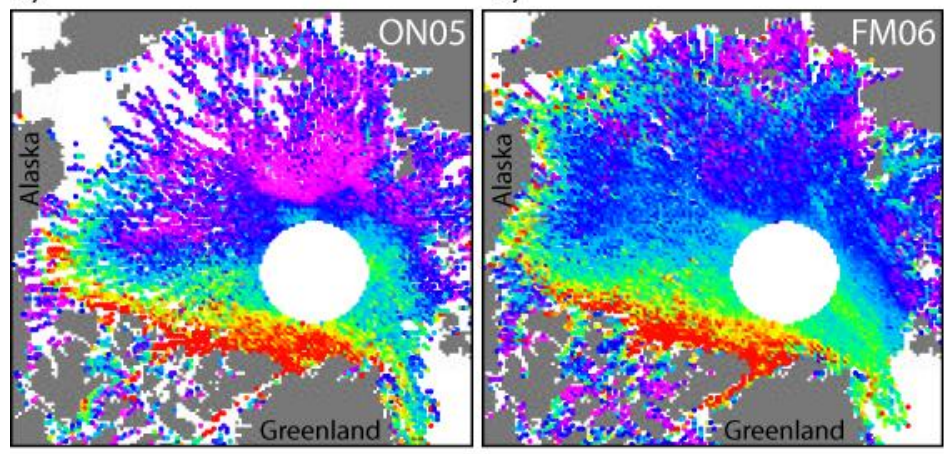

0.0 b)

$5.0 \mathrm{~m}$

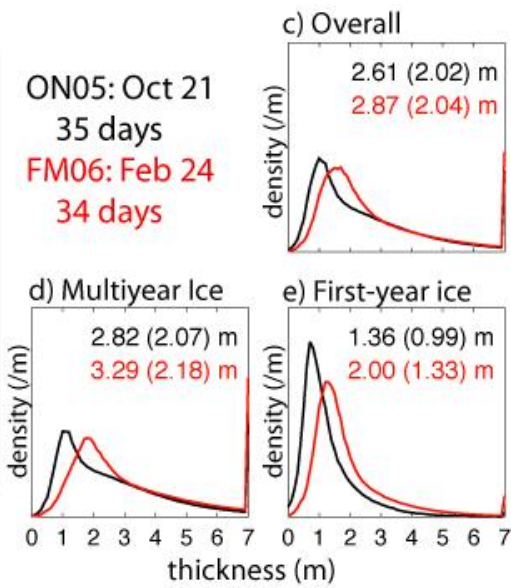

Figure 4. Sea ice thickness from ICESat. (a) Spatial field of ice thickness from ICESat data acquired over a 35-day period between October and November of 2005 (ON05). (b) Same as (a) but of data acquired in February and March of 2006 (FM06). The start day and duration of each campaign are shown above. (c) Overall ice thickness distributions of the Arctic basin in ONO5 (black) and FM05 (red). The quantities in the plot are the means and standard deviations (in brackets) of the thickness distributions. (d) Thickness distributions of the multiyear sea ice zone. (e) Thickness distributions of the first-year ice zone (from Kwok and Cunningham, 2008)

The CryoSat-2 mission will be launched in 2010. The radar altimeter on CryoSat will also be measuring the freeboard of ice and thereby thickness of floating sea ice. Use of Synthetic Aperture technique (SIRAL: SAR / Interferometric Radar Altimeter) shall enable measurements of high spatial resolution $(250 \mathrm{~m})$ compared to standard altimeters (see http://www.esa.int/esaLP/). The upcoming CryoSat-2 and ICESat-2 missions, both with primary scientific objectives of addressing changes in the Arctic sea ice thickness, will provide good coverage of this parameter into the next decade.

\section{ICE MONITORING USING SAR DATA}

\subsection{Ice type, deformation, and drift}

The RADARSAT Geophysical Processor System (RGPS) produces sea ice motion, deformation, and estimates of thickness from RADARSAT imagery [13]. Narrow quasi-linear features of the scale of kilometers to hundreds of kilometers can be seen as sharp discontinuities separating regions of uniform ice motion in the high-resolution RGPS deformation fields. These features are expressions of one of three kinematic processes (openings, closings, or shear) that control the sea ice thickness distribution. These largescale patterns are keys in understanding of the sea ice dynamics and its role in a declining ice cover. In addition, RGPS tracks a large number of Lagrangian elements of sea ice over a season for determining their ice age and ice thickness. It is shown that deformationrelated ice production is much higher in seasonal ice compared to the thicker multiyear ice [25]. With increasing coverage of thinner seasonal ice increased total deformation of the Arctic sea ice can be expected.

\subsection{Ice thickness estimation}

Altimeter data, like ICESat and Cryosat, have a limited spatial and temporal resolution and limited accuracy for tactical sea ice thickness monitoring especially in seasonal ice zones, which have relatively thin ice covers. For the Baltic Sea operational SAR-based ice thickness estimation algorithms have been developed [28]. SAR data from RADARSAT and Envisat ASAR are used in combination with traditional ice charts drawn by ice analysts to derive accurate thickness information. The algorithm refines the ice chart utilizing the SAR data to produce a chart with higher spatial resolution. Conceptually the approach is similar to the RGPS. The method will be extended to other areas where there is access only to modelled ice thickness values instead of an ice chart [29].

\subsection{Multisensor SAR}

Historically SAR observations of sea ice have been limited to single "channel" imagery. However, for a given sea ice mapping task, one frequency may be more suitable than another. With the new generation of 
SAR missions (e.g. RADARSAT-2, Sentinel-1, PALSAR (Phased Array type L-band Synthetic Aperture Radar), TerraSAR-X) it will be possible to combine data from several SAR missions with combinations of frequency, incidence angle, resolution and polarization. Some expected advantages of utilizing different frequencies and combinations of different polarizations are [30] [31] and [32]: 1) Coand cross-polarization data can be combined to obtain ice type classification and feature extraction, and to reduce ambiguity in ice-water discrimination. 2) The intensity contrast between deformed ice and smooth level ice floes is higher at L-band than at C/X-band, which is of advantageous for estimation of ridge density and ice drift. 3) The determination of floe boundaries during summer time may succeed better with L-band than $\mathrm{C} / \mathrm{X}$-band data because of the larger penetration depth. 4) X-band is in many cases more effective than L/C-band in separating thin ice types due to its larger backscattering intensity range. Carefully conducted field campaigns together with backscatter modeling will be necessary to understand the potential of multisensor/-frequency SAR.

\section{ICE ALBEDO AND SNOW COVER}

Numerical modelling studies have indicated that a time dependent description of surface albedo is critical for the realistic seasonal evolution of snow and ice thickness. The inaccuracy of albedo causes modelling errors in the onset of snow and ice melt, snow and ice mass balance, and the annual equilibrium ice thickness. For the future evolution of the Arctic Sea ice cover during the 21 st century, climate models show a large scatter between predictions [33]. Also, simulations of prevailing climate produce largest errors at high latitudes [34]. One reason for this is the inaccuracy of the snow/ice surface albedo. Hence, there is need for more observations on the snow/ice albedo feedback. Current surface albedo algorithms are based on optical data. Modelling experiments suggest that the optical albedo products have a potential applicability in the study of the snow and sea ice mass balance [35]. However, the long periods of low sun elevation in the polar areas limit the possibility to estimate the surface albedo using optical data. Therefore, a possibility to estimate the surface albedo using microwave data would be valuable. For sea ice it has been shown that SAR data can be used for surface albedo retrieval, because the aging of the snow and ice shows up both in the albedo and the backscatter. Inversion of surface shortwave albedo from C-band SAR imagery over smooth Arctic Ocean first-year ice is in principle possible throughout the melt season [36]. Additionally, C-band SAR derived surface albedo ingested into the thermodynamic sea ice model could improve sea ice simulations to better predict the timing of seasonal ice break-up. Time series evolution of C-band SAR data can be used to approximate the dates of melt onset and pond onset for seasonal ice [37] and for multiyear ice [38]. QuikSCAT Ku-band dual-polarized ( $\mathrm{HH}$ and VV) scatterometer time series can provide a second estimate of the melt ponds in addition to identifying the drainage state that is difficult to detect by singlepolarization SAR [5]. Although the potential of microwaves in surface albedo retrieval has been demonstrated in case studies, no quantitative physical link between the surface properties and the optical and microwave remote sensing signatures has been yet established.

Accurate estimation of snow depth on sea ice is important when measuring sea ice thickness. It is necessary to know the snow component of the freeboard measured by the altimeter in order to determine the true freeboard of the sea ice. Properties of snow cover affects how the underlying ice is seen by space-borne instruments. Snow thickness data is needed in coupled ocean-sea ice-atmosphere models. Currently the only operational snow thickness product is based on AMSR-E data [39]. This product has been assessed to yield dry snow thickness up to $50 \mathrm{~cm}$ with about $5 \mathrm{~cm}$ accuracy for smooth first-year ice. More accurate snow thickness estimation could be obtained using theoretical emissivity modeling and a thermodynamic snow/ice model in combination with the radiometer data. The snow thickness values could be interpolated to finer spatial resolution with segmented SAR images. Combination of backscatter statistics at different frequency bands may also provide independent qualitative estimation of snow thickness. In the marginal sea ice zones snow cover may become moist or wet even in the middle of the winter due to warm air advection. Moist snow cover may mask underlying sea ice in SAR images and decrease the ice classification capability of SAR. Estimation of snow cover volumetric wetness is therefore needed. This may be possible with combination of snow process and thermodynamic snow/ice models, high frequency SAR data (e.g. X- or Ku-band) and radiometer data.

\section{MANUAL ICE CHARTS}

The operational sea ice services produce charts based on a manual interpretation of satellite data. Today these are primarily based on SAR together with optical imagery, e.g. AVHRR (Advanced Very High Resolution Radiometer) and MODIS (Moderate Resolution Imaging Spectroradiometer). Interpretation of satellite imagery and subsequent mapping is carried out by experienced ice analysts. The ice charts are primarily used for strategic and tactical planning within the offshore and shipping community and are not focused on producing consistent long-term climate records. Demands are for detailed high quality. Manual ice charts are considered the best quality-controlled sea 
ice information source and are used as validation of automatic generated data sets (e.g. http://saf.met.no/validation/). Manual ice charting has been conducted during several decades before satellite data became available. There are systematic observations in the Arctic back to the late 1800's, while observations in the Antarctic are scattered and spotty up to the satellite era. Early ice charts are based on ship observations and manned stations. The accuracy and quality is variable. Thus the quality of input data and analysis capabilities has changed considerably over time also during the satellite era. These changes have not always been well-documented. There are inconsistencies between different ice charts and satellite-based sea ice time series. Systematic intercomparison and standardized error estimates are required for the data sets to be used in re-analysis and climate studies.

In addition to formally interpreted ice charts, some users make direct use of the input satellite images. Advances in satellite ground segments and distribution facilities have made SAR imagery available in near real time. Whilst these products are not interpreted and require some user experience, they have been well received. These products are also crucial in the Antarctic where regular formal ice charts are not routinely available.

\section{DATA ASSIMILATION}

Maximum benefit of all available sea ice observations from different sensors requires optimal integration of each data source. Although retrieval algorithms may provide valuable information from individual satellites, they do not help with the difficult task of reconciling seemingly inconsistent information from multiple data sources. Similar problems exist in operational weather forecasting where data assimilation (DA) has been used for many years to prepare 3-D analyses of the atmosphere. DA can incorporate information from many sources and add value by objectively reconciling differences and ambiguities in observations and, through the use of numerical models, providing more complete and physically consistent sea ice and ocean analyses. Simpler objective analysis techniques have been used in various weather centers for many years to prepare analyses of surface conditions including sea ice. More advanced techniques include ensemble Kalman filters, e.g. [40], and variational techniques, e.g. [41]. The essence of these techniques is to use a prior estimate usually from a numerical model of the desired gridded fields as basis for the new analysis. This is combined with observations accounting for the expected errors in the prior estimate and the observations. To demonstrate the general behavior of a typical variational analysis step, the input and output fields of the analysis on 2 March 2007 are shown in
Fig. 5. The assimilation of the observations brings the analysis much closer to the total ice concentration from the ice chart, as shown in Fig. 5d. Although retrieved information can be used in these DA systems, it is also possible to use direct observations.

The product suite offered by operational ice services in the future will depend significantly on DA/modeling systems as increasing data volumes and client demand increase the need for automation. This will require developments in two main areas. The first is to develop techniques to incorporate as many observations as feasible. Currently more straightforward observations such as from passive microwave instruments, ice drift and manual ice charts, have been assimilated. Additional observations such as active radar, radiometer and weather satellites will be incorporated over the coming years. The second development area lies in improving the prior estimate or equivalently the forecasts provided by coupled atmosphere-ice-ocean models that propagate information from past observations. While these developments will likely fall short of completely automating ice services, they are expected to improve the operational product suite and possibly reduce overall costs.
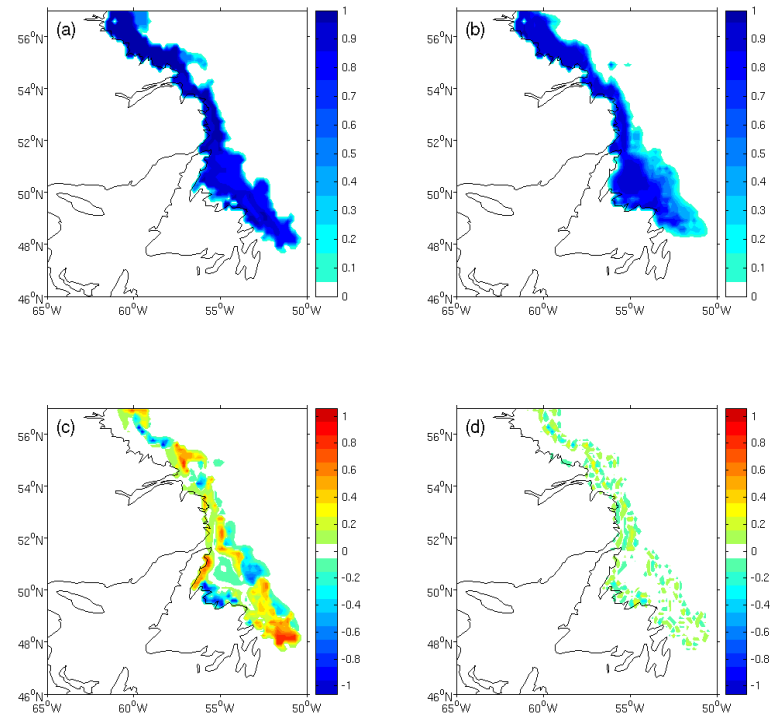

Figure 5. The input and output fields over a sub-region of a model domain for a typical 3D-Var analysis (2 March 2007 in the fourth 3D-Var experiment) are shown. $5 a$ and $5 b$ show the observations and background state for total ice concentration, respectively. $5 c$ and $5 d$ show the corresponding observation-minus-forecast and observation-minusanalysis fields for the total ice concentration, respectively. 


\section{DATA ACCESS}

The access to large-scale satellite data and sea ice products derived from these data is good: major operational data and information centers with easy access are e.g.: NSIDC (National Snow and Ice Data Center) (http://nsidc.org/), EUMETSAT OSI SAF (European Organisation for the Exploitation of Meteorological Satellites Ocean and Sea Ice Satellite Application Facility (http://saf.met.no/) and CERSAT (Center for Satellite Exploitation and Research), (http://cersat.ifremer.fr/). The national ice centers provide access to several regional fine scale products. Products can be also be found e.g. on http://www.polarview.org. Access to SAR data is more difficult due to high data volumes and costs, however ordering and access mechanisms are in place and working. It is likely that access to SAR data and SAR derived products will open up in the next decade, e.g. ESA (European Space Agency) will make the ENVISAT ASAR images freely available from November 2009 onwards. In the context of GMES (Global Monitoring for Environment and Security) SAR based sea ice products and SAR data will be available through MyOcean (http://www.myocean.eu.org). Developments during the last decade have moved toward a more open data policy and standardization of file formats and meta data as well as distribution tools. The European INSPIRE (Infrastructure for Spatial Information in the European Community) directive and efforts through IPY (International Polar Year), WMO, EU (European Union), GEO (Group on Earth Observations), etc. is pointing toward a free or open data access while promoting interoperability. This development is essential for progress in sea ice science and in general for efficient utilization of the investments in remote sensing.

\section{SUMMARY and recommendations}

This paper has given an overview of techniques and methods in extracting sea ice information from satellite data ranging from global to regional scales. As a summary the following recommendations are given.

- It is of great importance to secure future availability of operational passive microwave imaging ensuring continuation of the long global sea ice data record for climate monitoring.

- The access to SAR data for operational sea ice monitoring should be further developed and improved, e.g. through the GMES oceanographic programs.

- Coordinated programmes are needed to improve existing and develop new algorithms for retrieval of sea ice parameters.
- A main focus should be on development of integrated products from multiple algorithms and multiple sensors, e.g. to derive advanced parameters as volume fluxes and information on melting and sea ice albedo.

- Algorithms should be compared and validated against independent data. The validation should include both regular operational validation carried out on daily, weekly or monthly basis, and hindcast validation carried out with data available in delayed mode.

- For this it is necessary to improve access to validation datasets on standardized formats, e.g. following the development in connection to the International Polar Year.

- Further, it is important to develop and implement sea ice data assimilation and modelling techniques along with related observation operators for all useful satellite data.

- For sea ice data and algorithms it is necessary to provide more complete error estimates, which are needed both to create optimal fused and assimilated products as well as to extract longer time series of sea ice information.

- It is also important to track and archive source information for operational ice charts to better assess quality and consistency.

\section{REFERENCES}

1. Turner J, Overland J, 2009, Contrasting climate change in the two Polar Regions, Polar Research, Volume 28, Number 2, August 2009, pp. 146-164.

2. Steffen, K., Schweiger, A.J. 1991. NASA Team Algorithm for Sea Ice Concentration Retrieval from Defense Meteorological Satellite Program Special Sensor Microwave Imager: Comparison with Landsat Satellite Imagery. J. Geophys. Res, Vol. 96, no. C12, 21, 971 21,987 .

3. Andersen S., R. Tonboe, L. Kaleschke, G. Heygster, L. T. Pedersen (2007), Intercomparison of passive microwave sea ice concentration retrievals over the high-concentration Arctic sea ice, J. Geophys. Res., 112.

4. Comiso J.C, D.J. Cavalieri, C.L. Parkinson, P. Gloersen, (1997) Passive microwave algorithms for sea ice concentration: A comparison of two techniques. Remote Sens. Environ, 60, 357-384.

5. Howell, S. E. L., J. J. Yackel, R. De Abreu, T. Geldsetzer, and C. Breneman, (2005), On the utility of SeaWinds/QuikSCAT data for the estimation of the thermodynamic state of first-year sea ice, IEEE Trans. Geosci. Remote Sensing, 43(6), 1338-1350.

6. Breivik L.-A., S. Eastwood, Ø. Godøy, H. Schyberg, S. Andersen, R.T. Tonboe, (2001), Sea Ice Products for 
EUMETSAT Satellite Application Facility. Canadian Journal of Remote Sensing, Volume 27, No 5.

7. Giles K. A., S. W. Laxon, A. L. Ridout (2008), Circumpolar thinning of Arctic sea ice following the 2007 record ice extent minimum, Geophys. Res. Lett., 35.

8. Nghiem, S. V., I. G. Rigor, D. K. Perovich, P. ClementeColon, J. W. Weatherly, and G. Neumann, (2007), Rapid reduction of Arctic perennial sea ice. Geophys. Res. Lett., 34.

9. Tonboe R., L. Toudal, (2005), Classification of new-ice in the Greenland Sea using Satellite SSM/I radiometer and SeaWinds scatterometer data and comparison with ice model, Remote Sens. Environ, vol. 97.

10. Naoki, K., J. Ukita, F. Nishio, M. Nakayama, J. C. Comiso, and A. Gasiewski (2008), Thin sea ice thickness as inferred from passive microwave and in situ observations, J. Geophys. Res., 113, C02S16.

11. Martin, S., R. Drucker, R. Kwok, and B. Holt (2004), Estimation of the thin ice thickness and heat flux for the Chukchi Sea Alaskan coast polynya from Special Sensor Microwave/Imager data, 19902001, J. Geophys. Res., 109, C10012.

12. Dierking, W., J. Dall, (2008), Sea Ice Deformation State from Synthetic Aperture Radar Imagery, IEEE Trans. Geosci. Remote Sensing, 46( 8), 2197-2207.

13. Kwok, R. and G. F. Cunningham, (2002), Seasonal ice area and volume production of the Arctic Ocean: November 1996 through April 1997, J. Geophys. Res., 107(C10).

14. Fowler, C., W.J. Emery, and J. Maslanik, (2004). Satellite-derived evolution of Arctic sea ice age: October 1978 March 2003, IEEE Geoscience and Remote Sensing Letters, 1(2), 71-74.

15. Martin, T., and E. Augstein, (2000) Large-scale drift of Arctic sea ice retrieved from passive microwave satellite data. J. Geophys. Res., vol. 105 (C4), 87758788 .

16. Spreen, G., S. Kern, D. Stammer, R. Forsberg, and J. Haarpaintner, (2006), Satellite-based estimates of sea ice volume flux through Fram strait. Annals of Glaciology, vol. 44, 321-328.

17. Zhang, J., D. R. Thomas, D. A. Rothrock, R. W. Lindsay, and Y. Yu, (2003), Assimilation of ice motion observations and comparisons with submarine ice thickness data. J. Geophys. Res., vol. 108 (C6), 3170.

18. Liu, A. K. and D. J. Cavalieri, (1998) On sea ice drift from the wavelet analysis of the Defense Meteorological Satellite Program (DMSP) Special Sensor Microwave Imager (SSM/I) data. Int. J. Rem. Sens., vol. 19 (7), 1415-1423.

19. Kwok, R., A. Schweiger, D. A. Rothrock, S. Pang, and C Kottmeier, (1998) Sea ice motion from satellite passive microwave imagery assessed with ERS SAR and buoy motions. J. Geophys. Res., vol. 103 (C4), 8191-8214.
20. Girard-Ardhuin F., R. Ezraty, and D. Croizé-Fillon, (2008) Arctic and Antarctic sea ice concentration and sea ice drift satellite products at Ifremer/CERSAT. Mercator-Ocean Quarterly newsletter, January 2008.

21. Meier, W. N., J. A. Maslanik, and C. W. Fowler (2000), Error analysis and assimilation of remotely sensed ice motion within an Arctic sea ice model, J. Geophys. Res., 105(C2), 33393356 , doi:doi:10.1029/1999JC900268.

22. Kwok, R., G. F. Cunningham and S. S. Pang, (2004), Fram Strait sea ice outflow. J. Geophys. Res., 109, C01009.

23. Sandven, S., (2008), Sea ice monitoring in European Arctic Seas using a multisensor approach. Chapter in the book: Remote Sensing of the European Seas (Eds. Barale and Gade) Springer Science and Business Media B. V., pp. 487-498.

24. Fowler, C. (2003) updated 2007. Polar Pathfinder Daily $25 \mathrm{~km}$ EASE-Grid Sea Ice Motion Vectors, [list the dates of the data used]. Boulder, Colorado USA: National Snow and Ice Data Center. Digital media.

25. Kwok, R., G. F. Cunningham, H. J. Zwally, and D. Yi, (2007), Ice, Cloud, and land Elevation Satellite (ICESat) over Arctic sea ice: Retrieval of freeboard, $J$. Geophys. Res., 112, C12013.

26. Kwok, R., and G. F. Cunningham, (2008), ICESat over Arctic sea ice: Estimation of snow depth and ice thickness, J. Geophys. Res., 113, C08010.

27. Kwok, R., G. F. Cunningham, M. Wensnahan, I. Rigor, H. J. Zwally, and D. Yi (2009), Thinning and volume loss of the Arctic Ocean sea ice cover: 2003-2008, J. Geophys. Res., Volume 114, Issue C7.

28. Karvonen, J., M. Simila, J. Haapala, C. Haas, M. Makynen, (2004) Comparison of SAR Data and Operational Sea Ice Products to EM Ice Thickness Measurements in the Baltic Sea, Proc. IEEE International Geoscience and Remote Sensing Symposium (IGARSS'04), v. V, pp. 3021-3024.

29. Karvonen, J., B. Cheng, M. Simila, M. Hallikainen, (2008) Baltic Sea Ice Thickness Charts Based on Thermodynamic Snow/Ice Model, C-Band SAR Classification and Ice Motion Detection, Proc of the International Geoscience and Remote Sensing Symposium 2008 (IGARSS'08).

30. Onstott, R., (1992) SAR and scatterometer signatures of sea ice, in Microwave Remote Sensing of Sea Ice, Geophysical Mono. 68, F. Carsey, Ed., Washington, DC: Amer. Geophys. Union, pp. 73104.

31. Winebrenner, D. P., et al., (1992) Microwave sea ice signature modeling, in Microwave Remote Sensing of Sea Ice, Geophysical Mono. 68, F. Carsey, Ed., Washington, DC: Amer. Geophys. Union, pp. 137175.

32. Dierking, W., and T. Busche, (2006), Sea ice monitoring by L-band SAR: An assessment based on literature and comparisons of JERS-1 and ERS-1 imagery, IEEE Trans. Geosci. Remote Sensing, Vol. 44, No. 4, pp. 957-970. 
33. Sorteberg A., Katsov V., Walsh J. and Palova T, 2007:

The Arctic Surface Energy Budget as Simulated with the IPCC AR4 AOGCMs, Climate Dynamics, Volume 29, Numbers 2-3, 131-156, doi:10.1007/s00382-006$0222-9$.

34. Christensen, J.H., B. Hewitson, A. Busuioc, A. Chen, X. Gao, I. Held, R. Jones, R.K. Kolli, W.-T. Kwon, R. Laprise, V. Magaña Rueda, L. Mearns, C.G. Menéndez, J. Räisänen, A. Rinke, A. Sarr and P. Whetton, (2007): Regional Climate Projections. In: Climate Change 2007: The Physical Science Basis. Contribution of Working Group I to the Fourth Assessment Report of the intergovernmental Panel on Climate Change, Cambridge University Press

35. Cheng, B., T. Vihma, Z. Zhang, Z. Li and H. Wu. (2009) Snow and sea ice thermo dynamics in the Arctic: Model validation and sensitivity study against SHEBA data, Special Issue of Chinese J. Polar Sci. for Pacific Arctic Group (PAG) meeting, 2008.

36. Hanesiak, J.M., D.G. Barber, R.A. De Abreu and J.J. Yackel. (2001). Local and Regional Albedo Observations of Arctic First-Year Sea Ice During Melt Ponding J. Geophys. Res., 106(C1): 1005-101.

37. Yackel, J.J., D.G. Barber, and T.N. Papakyriakou. (2001). On the Estimation of Spring Melt in the North Water Polynya (NOW) using RADARSAT-1 SAR. Atmosphere-Ocean (NOW special issue). 39(3):195208.

38. Winebrenner, D. P., Nelson, E. D., Colony, R., and West, R. D., (1994) Observation of melt onset on multi-year Arctic sea ice using the ERS-1 synthetic aperture radar. J. Geophys. Res., 99, 22,425-22,441.

39. Comiso, J.C., D.J. Cavalieri, T. Markus, (2003), Sea ice concentration, ice temperature, and snow depth using AMSR-E data, IEEE Trans. Geosci. Remote Sensing, 41(2), 243-252.

40. Lisæter, K. A., J. Rosanova, and G. Evensen, (2003), Assimilation of ice concentration in a coupled iceocean model using the ensemble Kalman filter. Ocean Dynamics, 53 (4), 368-388

41. Caya, A., M. Buehner and T. Carrieres, (2010), Analysis and forecasting of sea ice conditions with threedimensional variational data assimilation and a coupled ice-ocean model, Journal of Atmospheric and Oceanic Technology, 27, 353-369.

doi:10.1175/2009JTECHO701.1 